\title{
Inequalities in child welfare intervention rates: the intersection of deprivation and identity
}

\author{
Paul Bywaters, Geraldine Brady, Tim Sparks and Elizabeth Bos \\ SURGE, Coventry University, Coventry, UK
}

Correspondence:

Paul Bywaters,

SURGE, Faculty of Business, The

Environment and Society,

Coventry University,

Priory Street,

Coventry CV1 5FB,

UK

E-mail: P.Bywaters@coventry.ac.uk

Keywords: age, child protection, child welfare, deprivation, disability, ethnicity, gender, inequalities

Accepted for publication: June 2014

\begin{abstract}
Child welfare systems internationally exhibit very large inequalities in a variety of dimensions of practice, for example, in rates of child protection plans or registrations and out-of-home care. Previous research in the midlands region of England (Bywaters; Bywaters et al.) has detailed key aspects of the relationship between levels of neighbourhood deprivation and intervention rates. This paper reports further evidence from the study examining the intersection of deprivation with aspects of identity: gender, disability, ethnicity and age. Key findings include a decreasing gender gap and a decreasing proportion of children in need reported to be disabled as deprivation increases. The data challenge the perception that black children are more likely than white to be in out-of-home care, a finding that only holds if the much higher level of deprivation among black children is not taken into account. Similarly, after controlling for deprivation and age, Asian children were found to be up to six times less likely to be in out-of-home care. The study requires replication and extension in order that observed inequalities are tested and explained. Urgent ethical, research, policy and practice issues are raised about child welfare systems.
\end{abstract}

\section{INTRODUCTION}

Child welfare systems internationally exhibit very large inequalities in a variety of respects (Bilson et al. 2013; Bywaters 2013; Bywaters et al. 2014; Eckenrode et al. 2014). For example, child protection plan (CPP) or registration rates varied between the four countries of UK from 24.7 per 10000 children to 46.8 per 10000 in $2013^{1}$. Child welfare inequalities, defined as 'unequal chances, experiences and outcomes of child welfare that are systematically associated with social advantage/disadvantage' (Bywaters 2013, p. 4), are seen in at least the following four aspects of practice.

- Inequalities in a parent's or child's chances of engagement with or intervention by child welfare services, reflecting diverse aspects of social position.

- Inequalities in the nature of child welfare interventions or provision for parents and/or children across different social groups or identities.
- Inequalities in childhood experiences and outcomes between different groups of children receiving welfare interventions and their counterparts in the wider population.

- Inequalities in outcomes as adults between different groups of children who received welfare interventions and those who did not.

These dimensions of child welfare inequalities reflect similar markers of inequalities in health: inequalities in chances of illness and premature death, in access to treatment, in the quality, nature and outcomes of treatment. In each case the underlying issue, the reason why these are characterized as inequalities rather than just a lottery, is the systematic impact of social structural factors, such as social class, neighbourhood deprivation and ethnicity, on health. Similarly, child welfare intervention rates are markers of the impact of social structures on child well-being.

However, until recently, inequalities in child welfare have rarely been described in such terms, rather being 
talked about as variations, differences, disparities or disproportionalities. This way of describing inequalities may have contributed to masking structural relationships that lie at the roots of child welfare practice, relationships between social inequalities, rates of state intervention in family life and outcomes for children (Hearn 2011). In turn, we suggest, this has contributed to a relative neglect in research, policy and practice of focus on fundamental causes (Phelan et al. 2010) of inequalities in access to child welfare services, in patterns of child welfare interventions and in outcomes, in favour of a 'narrowed ... discourse ... that emphasises blame on individual behaviour' (Stokes \& Schmidt 2011, p. 1119). Although 'everybody in the business knows' (Schorr 1992, p. 8) that access, interventions and outcomes are patterned by social inequalities, these factors are seen but not heard, universally familiar but rarely an explicit focus of policy and practice.

Nevertheless, in the last few years a focus on equity in access to, experience of and outcomes of child welfare structures and services has become more common (Tilbury \& Thoburn 2009). Much of this attention has been fuelled by an ongoing discussion of the relationship between socio-economic factors and racial identity in patterns of child welfare. For example, in the USA there has been a concern about the proportions of white, black and Latino children in the child welfare system (Hill 2007; Putnam-Hornstein et al. 2013; Wulczyn et al. 2013) and, in Australia, about rates of intervention and outcomes for children from the majority and indigenous populations (Bilson et al. 2013). In Britain, too, racial 'disproportionality' has been the focus of some attention. Owen \& Statham's review (2009, p. 1) stated that 'It has long been known that children from black and mixed heritage backgrounds are over-represented among children who are looked after and Asian children tend to be underrepresented'. Usually, across national boundaries, studies have reported an over-representation of indigenous and black or African-American children and an under-representation of other ethnic groups such as Latinos in the USA and 'Asian' children in the UK. Authors have continued to suggest a general 'overrepresentation' of ethnic minority children in care (Selwyn \& Wijedesa 2011) or in the child protection system (Ferguson 2014).

Over the past 10 years or so, researchers in the USA have begun to question these traditional certainties. Studies have shown that, when controlled for socio-economic status (SES), apparently higher rates are diminished or even reversed for black US children by comparison with low SES white children (Putnam-Hornstein et al. 2013). Indeed, recent evidence suggests that 'social disadvantage . . . is correlated with placement rates more for whites than for blacks' (Wulczyn et al. 2013, p. 73). Further, when controlled for SES, rates for Latino children remain significantly lower than those for white children (Putnam-Hornstein et al. 2013, p. 44), suggesting real differences between ethnic groups in 'maltreatment risk' for equivalent levels of deprivation, that disparities/inequalities are not just the result of systemic or practice bias.

Such investigations are valuable for two main reasons: they shed light on alternative explanations for the variable rates of intervention found between children of different identities and in different locations and they provide a more nuanced and, therefore, more precise account of working of the child welfare system. Hence, they create a firmer foundation for policy, planning, resource allocation, professional education and practice.

A key concept here is 'intersectionality'. As a recent review of the relationship between poverty and ethnicity put it:

People's experience is not shaped by one aspect of their identity alone but by a combination of elements. Gender, age, religion, disability, health, location and migration history can all be as important as ethnicity. They can change how ethnicity affects people's selfperception and treatment by others. In addition, class, skills and qualifications, personal outlook and experience can change the meaning that such demographic characteristics have. (Barnard \& Turner 2011, p. 4)

Studies of child welfare systems that focus on multiple dimensions of identity remain rare but to understand the complexities of the relationship between deprivation and differential rates of child welfare intervention, it is necessary to take into account aspects of identity. This means not only considering ethnic identity, but also other intersecting factors suggested by Barnard \& Turner (2011) above. However, in England, data are routinely recorded by child welfare services on only some dimensions of identity: age, gender, disability and ethnicity, but not, for example, religion or sexual orientation, either of which may be of importance to the children themselves and to how they are treated (Fish 2013). There is no internationally collected standard data set on child welfare systems.

This paper reports on issues of intersectionality as they inform the pattern and nature of child welfare inequalities in England. In 2013, research funded by 
the Nuffield Foundation began to examine differential rates of children's services interventions between and within local authorities (LAs) in England. A previous paper (Bywaters et al. 2014) reported on three key findings relating neighbourhood deprivation to rates of intervention.

- Very large inequalities in rates of children's services interventions were linked to deprivation. Children's chances of being a looked-after-children (LAC) or on a CPP varied greatly between neighbourhoods, as well as between LAs. Unequal rates were strongly statistically associated with measures of deprivation.

- A social gradient in child welfare interventions. Despite the large increase in rates associated with greater deprivation, children from families across the whole of society were LAC or on CPPs. Almost $40 \%$ of LAC or CPP came from outside the most disadvantaged $20 \%$ of neighbourhoods.

- An 'inverse intervention law' for child welfare. Overall a child's chances of a child welfare intervention increased significantly with deprivation but, comparing equivalent levels of neighbourhood deprivation, a child in a more affluent LA overall was more likely to be on a CPP or to be LAC.

Here we report findings on the intersection between neighbourhood disadvantage and four aspects of identity: disability, gender, ethnicity and age. The paper addresses only the first of the four markers of child welfare inequalities: unequal rates of intervention.

\section{METHODS}

Data were provided by 13 LAs in the English midlands, a mixture of urban boroughs and more rural counties. The participating LAs were responsible for nearly 1.2 million children aged $0-17,10.5 \%$ of all children in England, $10.6 \%$ of all children on a CPP and $11.3 \%$ of all LAC on 31 March 2012. Each LA reported on the age, gender, ethnic group and disability of all children in need (CIN), on a CPP and LAC on the given date. These data mirrored that routinely provided annually by LAs to produce national statistics. In addition, LAs identified the neighbourhood in which each child lived or, for LAC, of the address from which they became looked after. The neighbourhoods were those known as 'lower super output areas' (LSOAs), covering an average of 1500 residents, an element of the national structure of geographies on which official statistics are based.

Having amalgamated the data into LSOAs $(n=$ 3252), we analysed the relationships between rates of intervention and deprivation using population counts drawn from the 2011 Census and Index of Multiple Deprivation (IMD) scores for LSOAs published in 2010. The IMD is a broad measure of deprivation encompassing seven key dimensions and 38 indicators, not solely a measure of income. The primary form of analysis involved grouping LSOAs into deprivation quintiles ranked in terms of the national IMD scores. In subsequent tables and figures showing results for quintiles $1-5$, results for quintile 1 refer to all those neighbourhoods in the sample that were among the $20 \%$ least deprived neighbourhoods nationally. Quintile 5 refers to those neighbourhoods that were among the $20 \%$ most deprived neighbourhoods nationally. For much of this paper, data were analysed at middle layer super output area (MSOA) level because of small numbers in relevant cells once multiple variables are considered. MSOAs are groups of LSOAs with an average population of 7200 . The study methods are described in detail in the earlier paper (Bywaters et al. 2014).

\section{FINDINGS}

\section{Deprivation and the child population}

Central to this article is the thesis that understanding patterns of demand for and intervention by child welfare services requires examining the relationship between deprivation and aspects of identity. Although national and local policies, cultures and practices play an important part in determining the support families receive from child welfare services or their sometimes unwelcome interventions, structural factors frame patterns of demand. Our findings suggest that two key factors - deprivation and ethnicity - play the largest role in determining inequalities in rates of intervention, while other factors are also important contributors.

The UK is an unequal society. OECD data for 2010 show that the UK came 19th among European nations for the proportion of children living in relative poverty (http://www.oecd.org/social/family/database/ CWBM). In $2011,17 \%$ of UK children were living below the poverty line. This is anticipated to grow to 24\% (3.3 million children) before housing costs by 2020 (Brewer et al. 2011). Currently, multiple policies aimed at reducing state expenditure have worsened and will continue to worsen the circumstances of children (Reed 2012). Discussing inequalities rather than just poverty is significant here. Children's circumstances are more accurately described as being on a 
Table 1 Percentage of child population living in each quintile of neighbourhoods (MSOAs) by deprivation

\begin{tabular}{lccccc}
\hline Deprivation quintile & $1(\%)$ & $2(\%)$ & $3(\%)$ & $4(\%)$ & $5(\%)$ \\
$\begin{array}{l}\text { Child population } \\
\quad \text { in England }\end{array}$ & 19.4 & 18.3 & 18.5 & 20.1 & 23.7 \\
$\begin{array}{l}\text { Distribution of MSOAs, } \\
\quad \text { midlands sample }\end{array}$ & 11.0 & 20.0 & 19.0 & 21.0 & 28.0 \\
$\begin{array}{l}\text { Child population } \\
\quad \text { midlands sample }\end{array}$ & 12.1 & 15.9 & 15.7 & 18.1 & 38.2 \\
$\begin{array}{l}\text { Aged 0-4 } \\
\text { Birmingham }\end{array}$ & 10.1 & 14.1 & 15.1 & 18.7 & 42.0 \\
Warwickshire & 2.3 & 3.8 & 13.0 & 16.2 & 64.7 \\
& 30.3 & 24.4 & 20.5 & 16.8 & 8.0 \\
\hline
\end{tabular}

1 , most affluent $20 \%$ of neighbourhoods; 5 , most disadvantaged. MSOA, middle layer super output area.

continuum from the very poor to the very wealthy, rather than as a binary divide between those in poverty and those who are not.

The broad pattern nationally (Table 1 ) is that children are disproportionately found among relatively poor households. If distributed equally, each quintile of neighbourhoods should contain $20 \%$ of the population as a whole and of children but $23.7 \%$ of children were living in the most disadvantaged $20 \%$ of neighbourhoods at the 2011 Census. This pattern of excess deprivation in childhood was exaggerated in our midlands sample, which contained a disproportionate number of disadvantaged neighbourhoods. The combination of these two factors means that, in our sample, almost 2 in 5 children lived in the most disadvantaged fifth of neighbourhoods nationally. For very young children (aged 0-4) the over-representation was even greater: four times more young children lived in quintile 5 than in quintile 1.

There were also major differences in population patterns between LAs. In Birmingham and Sandwell over $60 \%$ of all children lived in the most deprived quintile, whereas in Warwickshire and Herefordshire this was true for less than $10 \%$ of children. Given that children in the fifth quintile were over seven times more likely to be LAC and over nine times more likely to be CPP compared with quintile 1 , the significance of the distribution of children among more or less deprived neighbourhoods for demand for children's services is apparent.

\section{Gender}

Overall, in our sample, boys were a little more likely than girls to be the subject of child welfare interventions. The gender gap (excess proportion of boys over girls) was $7.2 \%$ for CIN, and $5.5 \%$ for LAC, but only
$2.7 \%$ for CPP. These differences were spread remarkably evenly across age groups and CIN, CPP and LAC. The slightly greater preponderance of boys also applied to all five broad ethnic groups. Numbers of girls $(n=54)$ exceeded boys $(n=46)$ among children aged 16 and 17 on CPPs, but a handful of children could have reversed the pattern. There were also a very few more girls than boys on CPPs in the most disadvantaged decile. Indeed, there was some evidence of a diminishing gap between boys and girls as deprivation increased (see Fig. 1 for CIN), but this was a relatively slight relationship compared with other dimensions of identity, and only applied to CIN. For CIN, chisquare analysis of the number of boys and girls against quintile $\left(\chi^{2}[4]=11.10, P=0.025\right)$ supports the case that the gender gap reduced as deprivation increased. No obvious explanation for this was available from this study.

\section{Disability}

The proportion of children in England who are disabled is a contested area, partly because of differing definitions and data sources. Read et al. (2010, p. 142), in the most authoritative recent UK study of the prevalence of disability in childhood, defined it as 'children with a limiting longstanding (12 month duration or longer) illness, disability or infirmity experiencing one or more significant difficulties or health problems (. . including ... ) those who would have such difficulties or problems if they did not take medication/s'. They reported that $7.3 \%$ of children in the UK were disabled, $8.8 \%$ of boys and $5.8 \%$ of girls. However, the 2011 Census (Table DC3302EW) found that only $1.5 \%$ of children in England aged 0-15 were reported by parents to have a disability that limited their day-to-day activities 'a lot' with a further $2.2 \%$ having their activities limited 'a little'.

Mooney et al. (2008) found that LAs were unable to 'provide a reliable figure for the number of disabled children ... due to the difficulties LAs had in identifying and counting disabled children and the different definitions of disability applied' (p. 5). However, they estimated on the basis of a number of data sources that between $3.0 \%$ and $5.4 \%$ of all children in England were disabled.

The annual Children in Need census asks LAs to record whether a child is disabled or not using the following definition drawn from the Disability Discrimination Act 2005: 'a physical or mental impairment which has a substantial and long-term adverse effect on his ability to carry out normal day-to-day 
Figure 1 Gender gap for children in need: excess of boys over girls as percentage of total by deprivation quintile.

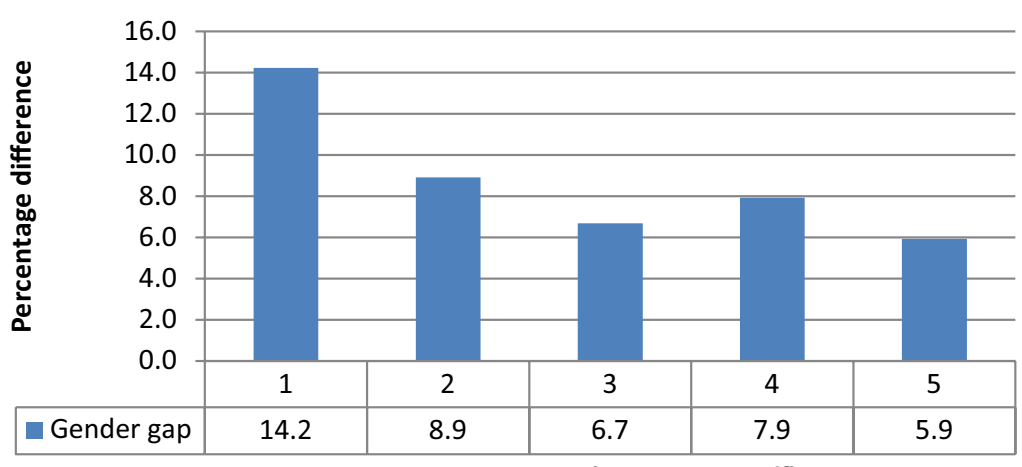

Deprivation quintiles: 1 = most affluent
Table 2 Percentage of CIN, CPP and LAC recorded as disabled in 13 LAs, midlands sample

\begin{tabular}{lccc}
\hline & Highest & Lowest & Average \\
\hline CIN & 23.6 & 6.7 & 13.1 \\
CPP & 12.1 & 0.0 & 2.3 \\
LAC & 23.2 & 0.5 & 8.2 \\
\end{tabular}

CIN, children in need; CPP, on child protection plans; LA, local authority; LAC, looked-after-children.

activities . . . the condition has lasted or is likely to last at least 12 months in order to be counted as a disability'. However, children who only 'receive mail outs (for example newsletters)' were excluded (Department for Education 2012, p. 7). This guidance was adopted for this study. Many, perhaps most, disabled children will not be receiving social care services and this is reflected in our finding that disabled children who were CIN constituted only $0.32 \%$ of all children in the participating LAs. Using Blackburn et al.'s (2010) data, less than 1 disabled child in 20 was designated a CIN.

Our findings, too, suggest very different practices between LAs in how disability was recorded. The proportion of CIN recorded as disabled varied from $6.7 \%$ to $23.6 \%$. This does not seem plausible as a real difference in prevalence between LAs. Similar large differences between LAs were found for CPP and LAC.

The overall proportion of children recorded as disabled is lowest for children on CPPs. This partly reflects a wider issue: rates of recorded disability are much lower for children under 5 than for other ages (Table 2). Blackburn et al. (2010) found that the UK rate of disability for under-fives was under half that for older children and suggested a number of reasons including possible under-recording. Diagnoses of disability may take some time to be confirmed, with more cases emerging as children enter school. In our sample, almost $45 \%$ of all children on CPPs were under 5, compared with less than $30 \%$ for CIN and LAC. An alternative explanation is that the focus on child protection over-rides attention to issues of disability. It again seems implausible that children on CPPs are actually less likely to be disabled than CIN or LAC.

Overall, the proportion of Asian CIN recorded as disabled was almost twice (24\%) than for the other ethnic groups (12.5\%). A similar difference was found for CPP but among LAC the proportion of Asian children who were disabled was lower than for other ethnic groups. However, in both these latter cases numbers were very small $(n<20$ for disabled Asian children).

As Table 3 (for CIN alone) and Fig. 2 (for CIN, CPP and LAC) indicate, the intersection of disability and deprivation appears to show progressively lower proportions of disabled children as deprivation increases. Disabled children in more affluent areas were more likely to be CIN than disabled children in more deprived areas. Given the evidence that disabled children live in 'substantially more disadvantaged material circumstances than () non-disabled children' (Blackburn et al. 2010, p. 9), this is the reverse of what would be expected. It is, perhaps, another example of Tudor Hart's (1971) inverse care law applying to child welfare services (Bywaters et al. 2014).

Although a similar but shallower gradient can be seen (Fig. 2) for CPP and LAC, the relationship between intervention rates and deprivation is not statistically significant (for LAC: $F[1,12]=1.91, P=$ $0.192)$, with numbers very small. The difference in gradient between CIN, CPP and LAC might be because parents of disabled children seek services that require CIN status but not for their child to be either on a CPP or a LAC, with parents from more affluent 


\begin{tabular}{lcccc}
\hline Age & CIN & CPP & LAC & $\begin{array}{c}\text { Blackburn et al. } \\
\text { estimates for UK }\end{array}$ \\
\hline $0-4$ & 3.6 & 0.9 & 1.8 & 3.7 \\
$5-9$ & 12.3 & 2.8 & 6.3 & 8.2 (age 5-11) \\
$10-15$ & 19.4 & 4.0 & 12.7 & 9.5 (age 12-15) \\
$16-17$ & 22.6 & 6.0 & 11.2 & 8.5 (age 16-18) \\
Number disabled & 3759 & 105 & 592 & \\
\% disabled & 13.1 & 2.3 & 8.2 & \\
& & & & \\
\hline
\end{tabular}

Table 3 Percentage of CIN, CPP and LAC, recorded as disabled, by age group and comparison with Blackburn et al. (2010)

CIN, children in need; CPP, on child protection plans; LAC, looked-after-children.

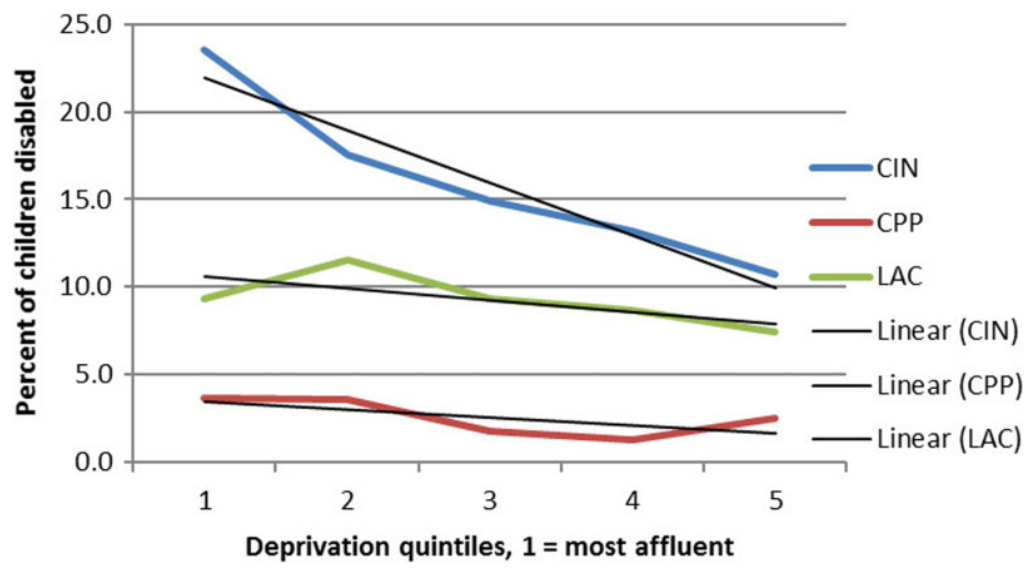

Figure 2 Percentage of children disabled, midlands sample, children in need, on child protection plans and looked-after-children. areas being more effective at securing services. This finding requires replication and explanation.

\section{Ethnicity}

Before presenting the findings on ethnicity, a number of caveats must be entered. For the purposes of statistics collected on CIN, CPP and LAC in England, the term 'black' is used to mean 'Caribbean, African or any other black background' and to exclude children of mixed heritage such as 'white and black Caribbean' or 'white and black African' (Department for Education 2012). The term 'Asian' refers to children of 'Indian, Pakistani, Bangladeshi or any other Asian background' and excludes children of mixed 'white and Asian background'. It can immediately be seen that these categories are problematic, as people of mixed heritage may identify themselves as black or Asian. It is also not known how consistently social workers or other social services staff collect these data.

A further important limitation is the amalgamation of ethnic groups into very broad categories. Such categories deny the diverse lived experience and identities of people in all ethnic groups and obscure the material circumstances of different subgroups. For example, in Wolverhampton over $70 \%$ of the 'Asian' population in the 2011 census identified themselves as of Indian heritage and only $10 \%$ as Pakistani, whereas in Birmingham 23\% identified as Indian and over $50 \%$ as Pakistani. Similarly, in Coventry over $70 \%$ of the population designated 'black' identified themselves as of African heritage compared with less than $25 \%$ in Sandwell. These differences are important as rates of poverty and many other factors vary substantially (Barnard \& Turner 2011). Future research needs to drill down further into ethnic groupings.

Those limitations aside, the aggregate national data for 2012 (Table 4) show a pattern similar to that reported by Owen \& Statham (2009) for the period 2003 to 2006 . That is, there were substantially higher rates of CIN and LAC for black children than for white but a much closer relationship for CPP, with children of mixed heritage experiencing the highest rates. Significantly lower rates were reported for Asian children in all three forms of intervention.

The overall data for our midlands sample (Table 5) show both similarities and differences with the national data. Although LAC rates for black children were above those for white children, rates for both CPP and CIN were lower. Rates for children of mixed 
Table 4 Percentage of CIN who are disabled, by age group and deprivation quintile, midlands sample

\begin{tabular}{lrrrrrr}
\hline \multicolumn{7}{c}{ Deprivation quintile } \\
\hline Age group & \multicolumn{1}{c}{1} & \multicolumn{1}{c}{ 2 } & \multicolumn{1}{c}{3} & \multicolumn{1}{c}{4} & \multicolumn{1}{c}{5} & \multicolumn{1}{c}{ All } \\
$0-4$ & 7.1 & 5.3 & 4.5 & 3.3 & 3.0 & 3.6 \\
$5-9$ & 25.6 & 14.4 & 12.9 & 13.2 & 10.0 & 12.3 \\
$10-15$ & 29.5 & 24.2 & 21.5 & 19.9 & 16.5 & 19.4 \\
$16-17$ & 30.3 & 29.7 & 23.5 & 20.5 & 20.2 & 22.6 \\
All & 23.5 & 17.6 & 14.9 & 13.2 & 10.7 & 13.1 \\
& & & & & & \\
\hline
\end{tabular}

CIN, children in need.

Table 5 CIN, CPP and LAC rates per 10000 children by ethnic group at 31.3 .12 (England)

\begin{tabular}{rrrrrrr}
\hline & White & Mixed & Asian & Black & Other & All \\
\hline CIN & 306.6 & 559.6 & 197.0 & 493.3 & 318.4 & 315.5 \\
CPP & 37.0 & 77.0 & 22.7 & 40.5 & 20.7 & 37.1 \\
LAC & 59.2 & 135.3 & 27.6 & 87.3 & 50.4 & 60.4 \\
& & & & & & \\
\hline
\end{tabular}

Sources: Department for Education and ONS Annual Population Survey October 2011-September 2012. CIN, children in need; CPP, on child protection plans; LAC, looked-after-children.

Table 6 CIN, CPP and LAC rates per 10000 children by ethnic group, midlands sample

\begin{tabular}{lrrrrrr}
\hline & White & Mixed & Asian & Black & Other & All \\
\hline CIN & 253.7 & 351.5 & 109.4 & 226.7 & 298.9 & 235.8 \\
CPP & 39.5 & 62.9 & 21.6 & 34.1 & 37.7 & 37.7 \\
LAC & 64.4 & 122.7 & 17.7 & 71.9 & 51.6 & 60.5 \\
& & & & & & \\
\hline
\end{tabular}

CIN, children in need; CPP, on child protection plans; LAC, looked-after-children.

heritage were the highest in each form of intervention whereas rates for Asian children were lowest.

However, examining this broad picture in more depth, a central issue is the distribution of the population of ethnic groups by deprivation. Although all children were over-represented in the most disadvantaged quintile of neighbourhoods, there was a striking difference between white and other ethnic groups in this respect (Table 6). Over two-thirds of Asian children and over three-quarters of all black children lived in the most disadvantaged $20 \%$ of neighbourhoods. By contrast little more than a quarter of all white children lived in these areas.
Table 7 Sample population by ethnic group and deprivation quintile - percentages

\begin{tabular}{|c|c|c|c|c|c|c|}
\hline Quintiles & 1 & 2 & 3 & 4 & 5 & All \\
\hline White & 15.1 & 19.7 & 18.2 & 19.3 & 27.8 & 100.0 \\
\hline Mixed & 6.9 & 9.3 & 12.1 & 18.3 & 53.3 & 100.0 \\
\hline Asian & 4.1 & 5.3 & 8.7 & 14.3 & 67.5 & 100.0 \\
\hline Black & 1.5 & 2.9 & 6.3 & 12.7 & 76.5 & 100.0 \\
\hline Other & 5.2 & 6.1 & 8.6 & 16.3 & 63.8 & 100.0 \\
\hline All & 12.1 & 15.9 & 15.7 & 18.1 & 38.2 & 100.0 \\
\hline
\end{tabular}

So, after controlling for deprivation by comparing ethnic groups within each deprivation quintile (Table 7), it is not black children who were overrepresented in rates of CIN, CPP or LAC but white children and those of mixed heritage. Black rates in neighbourhoods in quintile 5 , where over $76 \%$ of all black children were living, were around half of those for white children for CIN and CPP and less than two-thirds for LAC. It is only because so many black children were living in the most deprived neighbourhoods where intervention rates were higher that it appears that they are over-represented in the system overall. Because previous studies of black children's chances of being a LAC have not taken the levels of deprivation in the population into account, a misleading impression has been established over many years.

Previous research has detailed the underrepresentation of Asian children in child welfare interventions (Owen \& Statham 2009). Comparing Asian and white children at the same level of deprivation greatly increases the size of the disparity (Table 7). In quintile 5, where two-thirds of Asian children lived, CPP rates for Asian children were three times lower than those of white children and LAC rates around six times lower. The ratios in quintile 4 were approximately 2.5 and 4.5, respectively. Explanations for such very large differences have been mooted but not yet demonstrated. The previously observed gap between white and mixed heritage children is also reduced, although still present in the most disadvantaged fourth and fifth quintiles where over $70 \%$ of mixed heritage children were living.

Figure 3 shows ethnic differences in LAC rates across the whole midlands sample (excluding the 'other' ethnicity group because of low numbers). A number of features of our analysis can be seen here. First, this graphically represents the much higher rates among white and mixed heritage children in the fourth and fifth quintiles, compared with Asian and black children. Second, it can be seen that the gradi- 


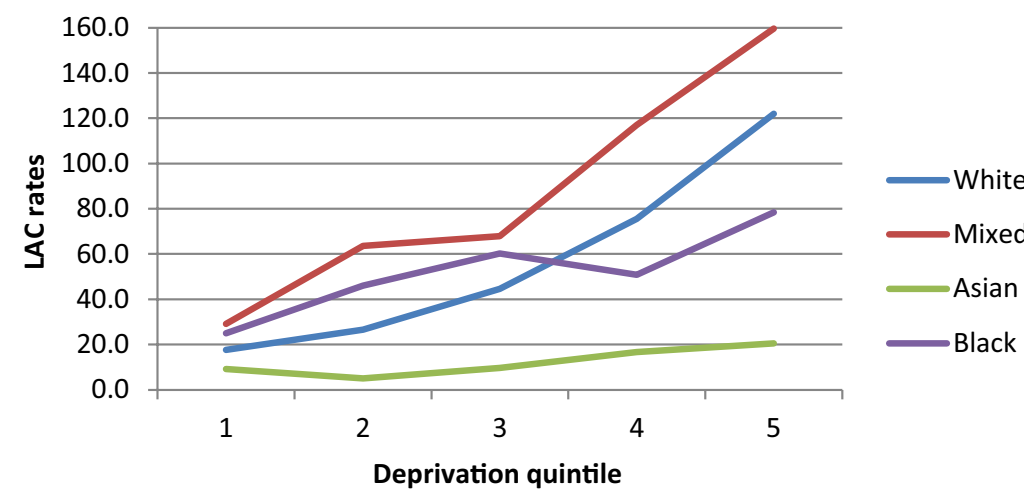

\begin{tabular}{lccccccccr}
\hline & \multicolumn{3}{c}{ CIN } & \multicolumn{3}{c}{ CPP } & \multicolumn{3}{c}{ LAC } \\
\hline Quintile & 4 & 5 & All & 4 & 5 & All & 4 & 5 & All \\
White & 295.9 & 428.0 & 253.7 & 42.4 & 76.8 & 39.5 & 75.5 & 122.1 & 64.4 \\
Mixed & 358.0 & 426.2 & 351.5 & 55.3 & 80.2 & 62.9 & 117.0 & 159.6 & 122.7 \\
Asian & 107.8 & 120.1 & 109.4 & 17.8 & 25.5 & 21.6 & 16.7 & 20.4 & 17.7 \\
Black & 261.4 & 223.3 & 226.7 & 29.9 & 35.3 & 34.1 & 50.8 & 78.3 & 71.9 \\
Other & 272.4 & 305.6 & 298.9 & 48.8 & 36.3 & 37.7 & 40.7 & 59.0 & 51.6 \\
All & 274.4 & 320.2 & 235.8 & 39.8 & 58.1 & 37.7 & 69.4 & 91.2 & 60.5 \\
& & & & & & & & & \\
\hline
\end{tabular}

CIN, children in need; CPP, on child protection plans; LAC, looked-after-children.
Figure 3 Looked-after-children rates by ethnic group and deprivation quintile.

Table 8 CIN, CPP and LAC rates by ethnic group and deprivation quintile, midlands sample ent - a measure of the strength of the relationship between deprivation level and rates - is steeper for white and mixed heritage children than for black and Asian children. This finding requires further confirmation, especially as the numbers of black and Asian children in quintiles 1-3 are small, only 57 children in all. However, it may mirror Wulczyn et al.'s (2013, p. 73) conclusion that in the USA that 'social disadvantage ... is correlated with placement rates more for whites than blacks'. Again, explanation is required. Third, the graph suggests that in neighbourhoods of low deprivation, LAC rates for black children were higher than those for white. This, too, requires replication as the numbers involved were very small (just 29 black children).

The data also add detail to the 'inverse intervention law' reported previously (Bywaters et al. 2014). Although the inverse statistical relationship between overall IMD scores at the LA level and rates of intervention at any given level of deprivation holds true for white children, indeed the relationship is even stronger, it is not found for other ethnic groups, mirroring Wulczyn et al. (2013). This, like the shallower gradient, may reflect a less strong relationship between social disadvantage and welfare intervention rates among minority ethnic groups, for reasons as yet unknown.
Table 9 CPP rates by age and deprivation quintile, midlands sample

\begin{tabular}{lrrrrrr}
\hline Quintiles & 1 & 2 & 3 & 4 & 5 & All \\
\hline $0-4$ & 19.3 & 26.4 & 41.7 & 58.7 & 81.0 & 56.9 \\
$5-9$ & 10.6 & 21.5 & 32.4 & 42.7 & 65.0 & 42.6 \\
$10-15$ & 5.0 & 13.0 & 20.6 & 31.2 & 45.1 & 27.9 \\
$16-17$ & 2.1 & 5.4 & 6.3 & 8.5 & 9.8 & 7.2 \\
All ages & 9.5 & 17.6 & 27.8 & 39.8 & 58.1 & 37.7 \\
& & & & & & \\
\hline
\end{tabular}

CPP, on child protection plans.

\section{Age}

Age is a further dimension in unravelling inequalities in the child welfare system. Age is a significant variable in both CPP and LAC rates (Tables 8 and 9). As children age, their chance of being on a CPP fall, in all deprivation quintiles and overall. CPPs are much more common among children under 5 than when older and, at that age, CPP rates are close to LAC rates. It is the much greater drop in CPP rates as children age by comparison with LAC rates, which results in the lower overall CPP rate. For LAC, rates at a point in time are highest for the oldest children.

If you combine CPP and LAC rates - in our sample less than $2.5 \%$ of cases were duplicated - the overall 
rate at which the state intervenes most powerfully to safeguard children is quite similar at different ages after the early years but the balance shifts from CPP to LAC as the predominant form of intervention (Table 10). The nature of this interaction, for example, whether these are in a sense the same children at different ages or different children, is one that could be explored further and might have a bearing on arguments about early intervention. The patterns in which children move in and out of CPP or LAC status at different ages will be an important part of the emerging picture.

The proportion of children in different ethnic groups also varies with age. Tables 11 and 12 show how age, ethnicity and deprivation intersect to produce inequalities in intervention rates. Overall the

Table 10 LAC rates by age and deprivation quintile, midlands sample

\begin{tabular}{lcrrrrr}
\hline Quintiles & 1 & 2 & 3 & \multicolumn{1}{c}{4} & \multicolumn{1}{c}{5} & All \\
& & & & & & \\
\hline $0-4$ & 17.5 & 22.2 & 35.3 & 59.0 & 82.1 & 55.7 \\
$5-9$ & 11.4 & 18.2 & 28.9 & 54.8 & 74.8 & 47.6 \\
$10-15$ & 17.8 & 29.7 & 50.7 & 76.1 & 105.2 & 66.8 \\
$16-17$ & 32.0 & 44.6 & 66.7 & 110.1 & 119.0 & 83.9 \\
All ages & 17.9 & 26.7 & 42.7 & 69.4 & 91.2 & 60.5 \\
& & & & & & \\
\hline
\end{tabular}

LAC, looked-after-children.
CPP rate for white children was nearly twice that for Asian children. But for children under 5 in quintile 5, a white child was more than four times more likely to be on a CPP than an Asian child. Similarly, the higher rate for white compared with black children increases from a ratio of 1.2 overall, to 2.2 for all ages in quintile 5 in which most black and Asian children live, and to 2.6 for children under 5. Adding age to deprivation further increases the inequalities in rates between ethnic groups.

Similarly (Table 13), although the overall ratio of white to Asian LAC rates was 3.6, for the youngest children in quintile 5 , the ratio increased to 6.6. For black children, the slight excess of black compared with white children overall is much more than reversed for children under 10 in quintile 5, where the rate for white children was around twice that for black children.

\section{DISCUSSION AND CONCLUSIONS}

Some of our findings add detail while confirming previous evidence, some overturn long held assumptions, others raise new questions about the relationships between deprivation and intervention rates. Overall, our data underline the growing case that analysing child welfare intervention rates without taking detailed account of the intersection between depriva-
Table 11 CPP, LAC and combined numbers and rates by age group, midlands sample

Table 12 Age-adjusted inequalities in CPP rates by ethnicity, quintile 5

\begin{tabular}{|c|c|c|c|c|c|c|}
\hline & \multicolumn{2}{|c|}{ CPP } & \multicolumn{2}{|c|}{ LAC } & \multicolumn{2}{|c|}{ Combined } \\
\hline & Number & Rate & Number & Rate & Number & Rate \\
\hline $0-4$ & 1931 & 56.9 & 1890 & 55.7 & 3821 & 112.7 \\
\hline 5-9 & 1326 & 42.6 & 1482 & 47.6 & 2808 & 90.2 \\
\hline 10-15 & 1091 & 27.9 & 2611 & 66.8 & 3702 & 94.7 \\
\hline $16-17$ & 99 & 7.2 & 1157 & 83.9 & 1256 & 91.1 \\
\hline All & 4447 & 37.7 & 7140 & 60.5 & 11587 & 98.3 \\
\hline
\end{tabular}

CPP, on child protection plans; LAC, looked-after-children.

\begin{tabular}{lcccccc}
\hline Age & $0-4$ & $5-9$ & $10-15$ & $16-17$ & All Q5 & All quintiles \\
White & 112.6 & 87.4 & 57.1 & 13.4 & 76.8 & 39.5 \\
Mixed & 109.6 & 97.2 & 50.9 & 5.9 & 80.2 & 62.9 \\
Asian & 27.7 & 29.6 & 25.0 & 6.7 & 25.5 & 21.6 \\
Black & 43.2 & 40.5 & 33.7 & 0.0 & 35.3 & 34.1 \\
Other & 54.4 & 37.2 & 23.2 & 0.0 & 36.3 & 37.7 \\
All & 81.0 & 65.0 & 45.1 & 9.8 & 58.1 & 37.7 \\
Ratio: white/Asian & 4.1 & 3.0 & 2.3 & 2.0 & 3.0 & 1.8 \\
Ratio: white/black & 2.6 & 2.2 & 1.7 & NA & 2.2 & 1.2 \\
& & & & & & \\
\hline
\end{tabular}

CPP, on child protection plans. 


\begin{tabular}{lrrrrrc}
\hline Age & \multicolumn{1}{c}{ 0-4 } & \multicolumn{1}{c}{-9} & $10-15$ & $16-17$ & All Q5 & All quintiles \\
White & 110.0 & 106.9 & 140.0 & 137.5 & 122.1 & 64.4 \\
Mixed & 158.0 & 128.6 & 170.8 & 221.7 & 159.6 & 122.7 \\
Asian & 16.6 & 16.7 & 21.6 & 41.1 & 20.4 & 17.7 \\
Black & 53.4 & 56.4 & 107.7 & 130.9 & 78.3 & 71.9 \\
Other & 60.2 & 41.0 & 46.3 & 146.7 & 59.0 & 51.6 \\
All & 82.1 & 74.8 & 105.2 & 119.0 & 91.2 & 60.5 \\
Ratio: white/Asian & 6.6 & 6.4 & 6.5 & 3.3 & 6.0 & 3.6 \\
Ratio: white/black & 2.1 & 1.9 & 1.3 & 1.0 & 1.6 & 0.9 \\
& & & & & & \\
\hline
\end{tabular}

Table 13 Age-adjusted inequalities in LAC rates by ethnicity, quintile 5

LAC, looked-after-children.

tion and identity leads to a misleading conception of current child welfare systems. As Franzen et al. (2008, p. 1057) put it, 'Beware of reports of overrepresentation of minorities in child welfare populations if the figures are presented without adjustments for socio-economic background'.

We would draw four key points from the data.

1. For most kinds of intervention studied, there was a small excess of boys over girls and this was consistent across age and ethnic groups and types of intervention, with few exceptions. However, for CIN the gender gap reduced as deprivation increased.

2. Data recording on disability is unreliable. Unexplained differences between the proportions of disabled children among CIN, CPP or LAC, between LAs and between Asian and other ethnic groups need further examination. The proportion of CIN reported as disabled decreased as deprivation increased, contrary to expectations.

3. In this sample, ethnic minority children were very greatly over-represented in high deprivation neighbourhoods compared with white children. A more detailed examination of ethnic identity below the broad groupings would be valuable.

CIN, CPP and LAC rates for black children in quintiles 4 and 5, in which almost $90 \%$ of black children lived, were substantially lower than for white or mixed heritage children. Rates for Asian children in quintiles 4 and 5 were between 2.5 and 6 times lower than for white children. Evidence of a stronger relationship between deprivation and rates of intervention for white than black or Asian children was seen, echoing findings from the USA. The inverse intervention law was confirmed for white but not for black and Asian children, perhaps because of small numbers.

4. Controlling for age, deprivation and ethnicity increased the inequality in rates between white, Asian and black children in neighbourhoods of high deprivation. The greatest inequalities were found for children under 5 in quintile 5 .
Probably, the most striking findings concern the interplay of deprivation, ethnicity and age. They suggest that the question, 'Why are black children over-represented among LAC?' should be replaced with two others: 'Why are black children so concentrated in the most deprived neighbourhoods?' and 'Why are most black children substantially underrepresented among LAC (CIN and CPP) compared with white and mixed heritage children living in similarly deprived neighbourhoods?' These findings provide a new marker of ethnic inequalities in England: overall black children remain overrepresented in the state's most powerful interventions in family life, with at best uncertain outcomes, because they are so over-represented among children living in areas of the highest deprivation. Racialized inequalities in the distribution, extent and consequences of deprivation must come into focus for child welfare services and more broadly.

The gap in rates between white (black and mixed heritage) children and Asian children was already known but is now seen to be much greater in neighbourhoods where most Asian children live. Combining CPP and LAC rates shows that in quintile 5, 1 in 50 white children were receiving a CPP or LAC intervention at 31st of March 2012, 1 in 88 Black children and 1 in 218 Asian children. To reiterate, the intersection between the distribution of deprivation among children from different ethnic groups and patterns of statutory child welfare interventions has to be the subject of further study but also new policy and practice.

A fundamental question is whether higher rates or lower rates represent greater well-being for children (Tilbury \& Thoburn 2009; Bywaters et al. 2014). Crudely are black and Asian children underrepresented among children on CPPs and LAC because their needs are being neglected by service providers or because there are lower levels of maltreatment? Is there something about the way Asian and 
black families or communities bring up their children that results in relatively few interventions in areas of high deprivation? If so, what is there to be learnt? Or are services failing to reach children with negative short- and long-term consequences for their wellbeing and development? The study of health inequalities suggests that the degree of social inequality may be an explanatory factor beyond the effects of deprivation (Fone et al. 2007). Might the lower concentration of white children in deprived neighbourhoods (greater social inequality) be significant?

In any case, when such high proportions of black and Asian children are living in the most disadvantaged neighbourhoods, questions are raised about the nature of society and the role that social workers can play in reducing or reinforcing social inequalities. When rates of extremely expensive but sometimes lifesaving interventions differ by a factor of 6 between ethnic groups but the reasons are unknown, urgent ethical, research, policy and practice issues are raised about the child welfare system.

\section{ACKNOWLEDGEMENTS}

We wish to thank the Nuffield Foundation who funded the project; Eileen McLeod and Olwen Haslam for their valuable comments on earlier drafts of this paper; members of the Advisory Group, especially Cathy Ashley of the Family Rights Group; Dez Holmes of Research in Practice; and the participating local authorities who provided the data and gave consistent support to the work.

\section{REFERENCES}

Barnard, H. \& Turner, C. (2011) Poverty and Ethnicity: A Review of Evidence. Joseph Rowntree Foundation, York.

Bilson, A., Cant, R., Harries, M. \& Thorpe, D. (2013) A longitudinal study of children reported to the child protection department in Western Australia. British fournal of Social Work, doi: 10.1093/bjsw/bct164. advance access.

Blackburn, C., Spencer, N. \& Read, J. (2010) Prevalence of childhood disability and the characteristics and circumstances of disabled children in the UK: secondary analysis of the Family Resources Survey. BMC Pediatrics, 10, 21.

Brewer, M., Browne, J. \& Joyce, R. (2011) Child and Working-Age Poverty from 2010 to 2020. Joseph Rowntree Foundation, York.

Bywaters, P. (2013) Inequalities in child welfare: towards a new policy, research and action agenda. British fournal of Social Work, doi: 10.1093/bjsw/bct079. online advanced access.

Bywaters, P., Brady, G., Sparks, T. \& Bos, E. (2014) Child welfare inequalities: new evidence, further questions. Child $\mathbb{F}$ Family Social Work, doi: 10.1111/cfs.12154.
Department for Education (2012) Guidance notes for the completion of children in need census. Department for Education, London.

Eckenrode, J., Smith, E., McCarthy, M. \& Dineen, M. (2014) Income inequality and child maltreatment in the United States. Pediatrics, 133, 454-461.

Ferguson, L. (2014) 'Families in all their subversive variety': over-representation, the ethnic child protection penalty, and responding to diversity whilst protecting children. Studies in Law, Politics, and Society, 63, 43-87.

Fish, J. (2013) Social Work and Lesbian, Gay, Bisexual and Trans People. Policy Press, Bristol.

Fone, D., Dunstan, F., Lloyd, K., Williams, G., Watkins, J. \& Palmer, S. (2007) Does social cohesion modify the association between area income deprivation and mental health? A multilevel analysis. International fournal of Epidemiology, 36, 338345.

Franzen, E., Vinnerljung, B. \& Hjern, A. (2008) The epidemiology of out-of-home care for children and youth: a national cohort study. British fournal of Social Work, 38, 10431059.

Hearn, J. (2011) Unmet needs in addressing child neglect: should we go back to the drawing board? Children and Youth Services Review, 33, 715-722.

Hill, R. (2007) An analysis of racial/ethnic disproportionality and disparity at the national, state and county levels. Casey Family Programs, Seattle, WA.

Mooney, A., Owen, C. \& Statham, J. (2008) Disabled children: numbers, characteristics and local service provision. Department for Children, Schools and Families, London.

Owen, C. \& Statham, J. (2009) Disproportionality in child welfare. Thomas Coram Research Unit, London.

Phelan, J., Link, B. \& Tehranifar, P. (2010) Social conditions as fundamental causes of health inequalities: theory, evidence and policy implications. Fournal of Health and Social Behaviour, 51, S28-S40.

Putnam-Hornstein, E., Needell, B., King, B. \& Johnson-Motoyama, M. (2013) Racial and ethnic disparities: a population-based examination of risk factors for involvement with child protective services. Child Abuse and Neglect, 37, 33-46.

Read, J., Blackburn, C. \& Spencer, N. (2010) Disabled children in the UK: a quality assessment of quantitative data sources. Child: Care, Health and Development, 36, 1, 130-141.

Reed, H. (2012) In the eye of the storm: Britain's forgotten children and families. Available at: http://www .actionforchildren.org.uk/media/4012135/in_the_eye_of_the _storm.pdf (accessed April 2014).

Schorr, A. (1992) The Personal Social Services: An Outside View. Joseph Rowntree Trust, York.

Selwyn, J. \& Wijedesa, D. (2011) Pathways to adoption for minority ethnic children in England - reasons for entry to care. Child E Family Social Work, 16, 276-286.

Stokes, J. \& Schmidt, G. (2011) Race, poverty and child protection decision making. British fournal of Social Work, 41, 11051121. 
Child welfare inequalities: deprivation, identity $\mathrm{P}$ Bywaters et al.

Tilbury, C. \& Thoburn, J. (2009) Using racial disproprotionality and disparity indicators to measure child welfare outcomes. Children and Youth Services Review, 31, 1101-1106.

Tudor Hart, J. (1971) The inverse care law. Lancet, 297, 405412 .

Wulczyn, F., Gibbons, R., Snowden, L. \& Lery, B. (2013) Poverty, social disadvantage, and the black/white placement gap. Children and Youth Services Review, 35, 65-74.

\section{NOTE}

1 Rates calculated from a NSPCC table of children on child protection plans or registers (http:// www.nspcc.org.uk/Inform/research/statistics/ unitedkingdom_wdf81294.pdf) and population data from the UK Census, 2011. 